This item was submitted to Loughborough's Research Repository by the author.

Items in Figshare are protected by copyright, with all rights reserved, unless otherwise indicated.

\title{
A numerical study on the effects of gas channel wettability in PEM fuel cells
}

PLEASE CITE THE PUBLISHED VERSION

http://dx.doi.org/10.1149/04801.0081ecst

\section{PUBLISHER}

(c) Electrochemical Society

\section{VERSION}

AM (Accepted Manuscript)

\section{PUBLISHER STATEMENT}

This work is made available according to the conditions of the Creative Commons Attribution-NonCommercialNoDerivatives 4.0 International (CC BY-NC-ND 4.0) licence. Full details of this licence are available at: https://creativecommons.org/licenses/by-nc-nd/4.0/.

\section{LICENCE}

CC BY-NC-ND 4.0

\section{REPOSITORY RECORD}

Alrahmani, Mosab, Rui Chen, and Salah S. Ibrahim. 2014. "A Numerical Study on the Effects of Gas Channel Wettability in PEM Fuel Cells". figshare. https://hdl.handle.net/2134/15641. 


\title{
A Numerical Study on the Effects of Gas Channel Wettability in PEM Fuel Cells
}

\author{
Mosab Alrahmani, Rui Chen, Salah Ibrahim \\ Department of Aeronautical and Automotive Engineering, Loughborough \\ University, Loughborough, LE11 3TU, UK
}

The wettability of channel walls and gas diffusion layer has a great influence on the water management of fuel cells. In this paper, a numerical study has been carried out to examine the effect of the wall and gas diffusion layer wettability on gas channels. The investigation employed a three dimensional numerical simulation using the volumeof-fluid (VOF) method to simulate the air-water flow in a straight micro-channel representing a gas channel in a PEM fuel cell. Nine combinations of wall and GDL wettabilities were investigated. Different wettability combinations were found to give different water behaviour. For fixed wall wettability, the pattern of the analysed parameters was changing between uniform cyclic, random cyclic and continuous. In addition, it was found that changing the GDL wettability has a greater impact on the analysed parameter compared to changing the wall wettability.

\section{Introduction}

Achieving and maintaining a high performance proton exchange membrane (PEM) fuel cell can be done by a proper water management (a sufficient membrane hydration and effective liquid droplet removal from catalyst layers, gas diffusion layers, and flow channels). Since liquid water is formed frequently on the gas diffusion layer (GDL) surface in the flow channels, liquid water is an important area of research in the PEM fuel cells (1-3). Water can be observed in the channels from two sources: 1 ) condensed water vapour from the inlet gas flow, and 2) water formed from the fuel cell chemical reaction in the reactions sites and transported from the cathode catalyst layer to the gas channels. The behaviour of water droplet in the PEM fuel cell gas channels has been studied through numerical simulation and experimental studies.

A number of experimental studies in the literature (4-6) showed the impact of material characterization on the liquid transport and flooding mechanism inside PEM fuel cells. Two studies $(4,5)$ investigated the liquid water behaviour in an actual operating fuel cell as a function of channel wall wettability. Different PTFE coatings were applied on the channel wall surface to change its wettability to get a better understanding on the flooding mechanism and through-plane liquid transport. In these studies, a liquid droplet formation was observed on the side walls in a hydrophobic coated channel, while a liquid film layer was formed by water stretch to the entire wall of the surface in a hydrophilic channel. Zhu et al. (6) used a high resolution X-ray imaging system to study the water movement in operating fuel cells with two types of graphite channels, hydrophobic and hydrophilic. After operating the cell for a period of time, different water behaviours were noticed. The surface properties of the channel walls and diffusion layer found to have significant impact on fuel cells water management through their experimental analysis. However, the manufacturing and 
processing cost can be reduced by using mathematical modelling to investigate the different phenomena in the fuel cell.

The volume-of-fluid (VOF) is a mathematical model used to understand the two-phase flow in gas channels because it is unique in the way it tracks the interface between the two phases. This method was developed in the early 1980s )7) and in the past decade it was a leading method in understanding the behaviour of water droplets in PEM fuel cells gas channels (812). The wettability effect on liquid droplet behaviour in micro-channels was studied qualitatively by Cai at el. (9). They found that the hydrophobicity is advantageous in moving the water droplets faster along a surface. However, a hydrophilic side walls are more beneficial to gas transportation from the channel into the MEA for both wettability scenarios, hydrophobic and hydrophilic, of the MEA from a qualitative point of view.

On the other hand, Zhu et al. (13-15) tracked the gas-liquid interface in a three-dimensional flow that included the water emergence into the channel. In their simulation, the MEA layer was neglected and they focused on a straight gas channel with a single pore in the bottom surface to inject liquid water and represent a GDL. In order to reduce computational cost, a small sized domain but representative of the real gas channels in a PEM fuel cell was used. They focused on the geometrical structure effect through a variety of parametric studies to analyse the liquid water behaviour. An analytical study was conducted on water droplet detachment diameter and time, and water coverage ratio with different channel cross-section geometries (13). Additionally, an analysis was conducted on a simple domain with various GDL contact angles to study its impact on water droplet detachment (14). Since the water was injected via a single pore, the droplet didn't reach the side wall and the side wall wettability effect was not included in the study. Recently, Zhu et al. (15) carried out more work to study the effect of the side wall wettability on the water droplet behaviour by shifting the pore to the side. They found that the behaviour of the water droplet only depends on the GDL wettability when it is located at the centreline, in addition to achieving the highest pressure drop. On the other hand, shifting the emergence location to the side wall showed more significant effect of the side wall wettability because of the unavoidable water droplet attached to it.

In this paper, a quantitative comparison is conducted on different wall and GDL wettability combinations for a flooded straight channel. Nine combinations of wettability have been mathematically solved and analysed. The analysis and comparison have been based on various aspects: 1) the total pressure difference between the inlet and outlet, 2) the amount of water contained in the channel, 3) the amount of water covering the GDL surface.

\section{Numerical Method}

\section{Governing Equations}

The simulated flow is assumed to be laminar, isothermal for the two phases in the microchannel, air and liquid water, because the range of operating fuel cell current densities correspond to a range of Reynolds number of 0 - 2077 (16). Heat generation and heat transfer are neglected to simplify the problem. Since the water dynamic behaviour is to be studied, the flow is transient. The governing conservation equations for mass and momentum are as follows:

$$
\begin{gathered}
\frac{\partial \rho}{\partial \mathrm{t}}+\nabla \cdot(\rho \overrightarrow{\mathrm{v}})=0 \\
\frac{\partial}{\partial \mathrm{t}}(\rho \overrightarrow{\mathrm{v}})+\nabla \cdot(\rho \overrightarrow{\mathrm{v}})=-\nabla p+\nabla \cdot\left[\mu\left(\nabla \overrightarrow{\mathrm{v}}+\nabla \overrightarrow{\mathrm{v}}^{\mathrm{T}}\right)\right]+\overrightarrow{\mathrm{F}}
\end{gathered}
$$


where $\vec{v}$ is the velocity vector, $\rho$ is the density of the fluid, $p$ is the pressure, and $\vec{F}$ is the external force.

Both equations are used to govern both the motion of air and liquid water in the flow channel. A three dimensional numerical model is implemented using the commercial CFD package, FLUENT 13.0.0 (17) with the volume-of-fluid (VOF) method, described in the following section, was used to determine the motion and deformation of liquid water in the channel.

\section{$\underline{\text { Volume-of-fluid (VOF) method }}$}

The VOF method uses a single set of momentum equations that is shared by the two phases. A volume fraction equation is added to track the interface between the phases. A volume fraction coefficient determines if a cell is occupied by a certain fluid (17)

$$
C_{k}=\left\{\begin{array}{lr}
0 & \text { (outside kth fluid) } \\
1 & \text { (inside kth fluid) } \\
0-1 & \text { (at the kth fluid interface) }
\end{array}\right.
$$

$\mathrm{C}_{\mathrm{k}}$ is the volume fraction coefficient at the $\mathrm{k}^{\text {th }}$ fluid, and the sum of the volume fraction coefficient is equal to 1 .

$$
\sum_{\mathrm{k}=1}^{\mathrm{n}} \mathrm{C}_{\mathrm{k}}=1
$$

The volume fraction equation needs to be solved at all cells in the computational domain

$$
\frac{\partial}{\partial \mathrm{t}}\left(\mathrm{C}_{\mathrm{k}} \rho_{\mathrm{k}}\right)+\nabla \cdot\left(\mathrm{C}_{\mathrm{k}} \rho_{\mathrm{k}} \overrightarrow{\mathrm{V}}_{\mathrm{k}}\right)=0
$$

The velocity field for the two-phase mixture in the channel is governed by the momentum equation presented earlier. Only one set of momentum equations are solved with the density and dynamic viscosity being averaged. They are computed, as follows, to account for the variable volume fractions of the two-phase air-water system considered here.

$$
\begin{aligned}
& \rho=\rho_{1}+C_{2}\left(\rho_{2}-\rho_{1}\right) \\
& \mu=\mu_{1}+C_{2}\left(\mu_{2}-\mu_{1}\right)
\end{aligned}
$$

where subscripts 1 and 2 represent the two phases, air and water, respectively.

Surface tension is accounted for and expressed in terms of the pressure difference across the interface. It is dependent on the surface tension coefficient, and implemented in the momentum equation as a body force:

$$
\begin{aligned}
& \overrightarrow{\mathrm{F}}: \Delta \mathrm{p}=\sigma \frac{1}{\mathrm{R}} \\
& \overrightarrow{\mathrm{F}}_{\mathrm{vol}}=\sigma \kappa_{\mathrm{k}} \frac{\rho \nabla \mathrm{C}_{\mathrm{k}}}{\frac{1}{2}\left(\rho_{1}+\rho_{2}\right)}
\end{aligned}
$$

where $\Delta \mathrm{P}$ is the pressure jump across the surface, $\sigma$ is the surface tension coefficient, and $\mathrm{R}$ is the radius of the surface curvature.

The curvature $\kappa_{\mathrm{k}}$ is computed from local gradients in the surface normal at the interface $\hat{\mathrm{n}}$ : 


$$
\kappa_{\mathrm{k}}=\nabla \cdot \hat{\mathrm{n}}=\nabla \cdot\left(\hat{\mathrm{n}}_{\mathrm{w}} \cos \theta_{\mathrm{w}}+\hat{\mathrm{t}}_{\mathrm{w}} \sin \theta_{\mathrm{w}}\right)
$$

where $\hat{n}$ is the unit vector normal to the interface between two phases near wall, $\hat{\mathrm{n}}_{\mathrm{w}}$ is the unit vector normal to the walls, $\hat{\mathrm{t}}_{\mathrm{w}}$ is the unit vector tangential to the walls, and $\theta_{\mathrm{w}}$ is the static contact angle at the wall where the contact angle is the angle at which a liquid/vapour interface meets a solid surface. If it is small, the liquid drop will spread on the surface; if it is large, a liquid drop will bead up.

The importance of the surface tension and gravitational force can be determined using dimensionless quantities, the Capillary number, the Weber number, and the Bond number.

The capillary number, $\mathrm{Ca}$, represents the relative effect of viscous forces to surface tension

$$
\mathrm{Ca}=(\mu v / \sigma)
$$

Weber number, We, represent the relative importance of the fluid's relative inertia, or kinetic energy, to the surface tension and may be written as follows:

$$
\mathrm{We}=\left(\rho v^{2} \mathrm{D} / \sigma\right)
$$

Bond number, Bo, represents the relative importance of surface tension compared to body forces, as follows:

$$
\text { Bo }=\left(\rho g D^{2} / \sigma\right)
$$

The water injection diameter $\mathrm{D}$ is used as the characteristic length with the density, viscosity, and surface tension coefficient of water. In the current simulations of the micro-channel conditions, the values for the above dimensionless numbers are $\mathrm{Ca}=1.4 \times 10^{-2}$, We $=0.7$, and $\mathrm{Bo}=3.4 \times 10^{-4}$. The low values of $\mathrm{Ca}$ and We numbers indicate that the surface tension dominate over viscous force and relative inertia which impose its importance. The low Bo indicates that the gravitational force is negligible.

The computational mesh and domain

The commonly used shape of fuel cell gas channels is rectangular. The bottom wall represent a GDL while the other sides' represent the walls of a fuel cell gas channel. The computational domain used in this study is shown in Figure 1 . The domain is $0.25 \mathrm{~mm} \times 0.25$ $\mathrm{mm}$ in cross section with a length of $1.50 \mathrm{~mm}$ (18). With water emerging via three pores from the GDL, air flow into the channel from one end to another. The pores are $0.05 \mathrm{~mm}$ in diameter, which is an accepted average of different GDL pore sizes $(18,19)$.

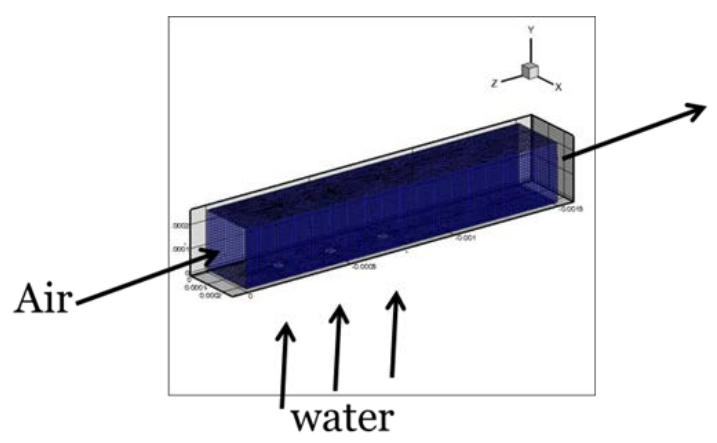

Figure 1. The computational domain used for all calculations. 
The computational mesh used in all simulations is orthogonal with a total number of 97,812 cells in all cases. A grid dependence analysis was conducted on the mesh by changing the number of cells by $25 \%$ and $40 \%$ on the case of $45^{\circ}$ wall contact angle and $135^{\circ} \mathrm{GDL}$ contact angle as well as changing the time step and they all showed a similar water droplet behaviour.

\section{$\underline{\text { Boundary and Initial Conditions }}$}

All calculations have been conducted here have the same boundary and initial conditions. Both the channel air and water pore inlet conditions have uniform velocity profiles. An outflow boundary condition was chosen for the channel outlet as the details of velocity and pressure were unknown at that location. The no-slip boundary condition (20) was imposed along the walls of the channel with specified surface tension and contact angle. For different wettabilities, different contact angles were assigned. Different contact angles result in different surface tension forces influencing the behaviour of water transport. The surface tension of water in contact with air is $0.0725 \mathrm{~N} / \mathrm{m}$ (21) while the contact angles were varied according to Table 1.

Table 1 . The calculated wettability combinations

\begin{tabular}{cccc}
\hline Wall & $\begin{array}{c}\text { Hydrophilic } \\
\mathbf{4 5}^{\circ}\end{array}$ & $\begin{array}{c}\text { Moderate } \\
\mathbf{9 0}^{\circ}\end{array}$ & $\begin{array}{c}\text { Hydrophobic } \\
\mathbf{1 3 5}^{\circ}\end{array}$ \\
\hline $\begin{array}{c}\text { Hydrophilic } \\
45^{\circ}\end{array}$ & Wall $\Theta=45^{\circ}$ & Wall $\Theta=90^{\circ}$ & Wall $\Theta=135^{\circ}$ \\
GDL $\Theta=45^{\circ}$ & GDL $\Theta=45^{\circ}$ & GDL $\Theta=45^{\circ}$ \\
$90^{\circ}$ & Wall $\Theta=45^{\circ}$ & Wall $\Theta=90^{\circ}$ & Wall $\Theta=135^{\circ}$ \\
Hydrophobic & GDL $\Theta=90^{\circ}$ & GDL $\Theta=90^{\circ}$ & GDL $\Theta=90^{\circ}$ \\
$135^{\circ}$ & Wall $\Theta=45^{\circ}$ & Wall $\Theta=90^{\circ}$ & Wall $\Theta=135^{\circ}$ \\
GDL $\Theta=135^{\circ}$ & GDL $\Theta=135^{\circ}$ & GDL $\Theta=135^{\circ}$ \\
\hline
\end{tabular}

The calculated inlet values are $10 \mathrm{~m} / \mathrm{s}$ of air flowing with a uniform velocity from the channel inlet and $1 \mathrm{~m} / \mathrm{s}$ of water injected with a uniform velocity from each pore on the GDL surface. The velocities correspond to Reynolds numbers of 160 and 50, respectively. The order of magnitude of air velocity is of the same order as flows encountered in automotive fuel cells stacks (22). The order of magnitude of water injection is of the same order used in ex-situ fuel cell experiments and corresponds to operation under high current density and water production rates $(23,24)$.

\section{Result and analysis}

The calculations are performed until the water starts to exit the computational domain for all wettability combinations. This is made in order to show any cyclic or continuous behaviour of the water dynamic motion and determine the duration that the water takes to exit the domain. The simulation was performed for an integration time of $3.5 \mathrm{~ms}$. The results from all calculations are compared based on three criteria that may affect the humidity of the air flowing in the channel and the speed of water movement along the channel for their importance on fuel cell performance, although heat transfer and humidity phenomena are not included in the simulations.

$\underline{\text { Pressure drop }}$ 
The pressure drop is the difference of the average-area total-pressure of air between the channel inlet and outlet. The total-pressure is calculated for each cell at both inlet and outlet boundaries. The pressure is averaged for all the cells at a surface to get the final pressure. The pressure drop is then calculated by finding the difference between the inlet and the outlet values.

Figure 2a gives a comparison of pressure drop of air flow between the inlet and outlet of the micro-channel for the general cases with different GDL wettability. For the hydrophobic case the air flow pressure drop is the highest among three cases because water volume forms droplets and blocks the air flow due to the surfaces high contact angle. It drops back after the detached coalesced droplet moves out of the channel. Afterward, another coalesced droplet is formed making a cyclic behaviour. For the moderate case the air flow pressure drop is significantly lower than the hydrophobic case however it still gives a cyclic behaviour because water volume forms wavy droplets that block less of the air flow. For the hydrophilic case the air flow pressure drop is the lowest because water volume forms a slug on the GDL due to the surface low contact angle and it has continuous pressure drop behaviour.

Figure 2b,c,d shows the effect of wall wettability on the pressure drop between the inlet and the outlet of the micro-channel for different GDL wettabilities (i.e. hydrophilic, moderate, and hydrophobic). Figure 2b shows that for a hydrophilic GDL the change in wall wettability is insignificant as the pressure increases continuously as time progresses until a water film layer is formed on the GDL surface where the average pressure drop is 500 Pa. Figure 2c shows a random cyclic pressure drop behaviour for a moderate GDL with all wall wettabilities. The formation and continuous movement of wavy droplets causes the random cyclic behaviour of the pressure drop where the average peak pressure drop is $\sim 700 \mathrm{~Pa}$. Figure $2 \mathrm{~d}$ shows a cyclic behaviour of pressure drop in a micro-channel with a hydrophobic GDL, in addition to a more significant role to wall wettability compared to the other GDL wettabilities. The pressure drop increases when the micro-channel is blocked due to water droplets coalescence and since the GDL is hydrophobic the droplets are moved easily by the gas flow. The first coalesced water droplet for a hydrophilic wall experience the highest pressure drop because of the wall attraction to water that makes it to spread on the microchannel cross-section. The second coalesced water droplet for a hydrophilic wall doesn't experience as high pressure drop because of water hysteresis that causes it to spread along the walls as soon as the droplet is coalesced. On the other hand, for a hydrophobic wall the second coalesced water droplet causes a higher pressure drop than the first coalesced water droplet because of more water content from the first water inlet due to an early previous droplet detachment. The figure (cf. Figure 2c) shows an average peak pressure drop of $\sim 2000$ Pa.
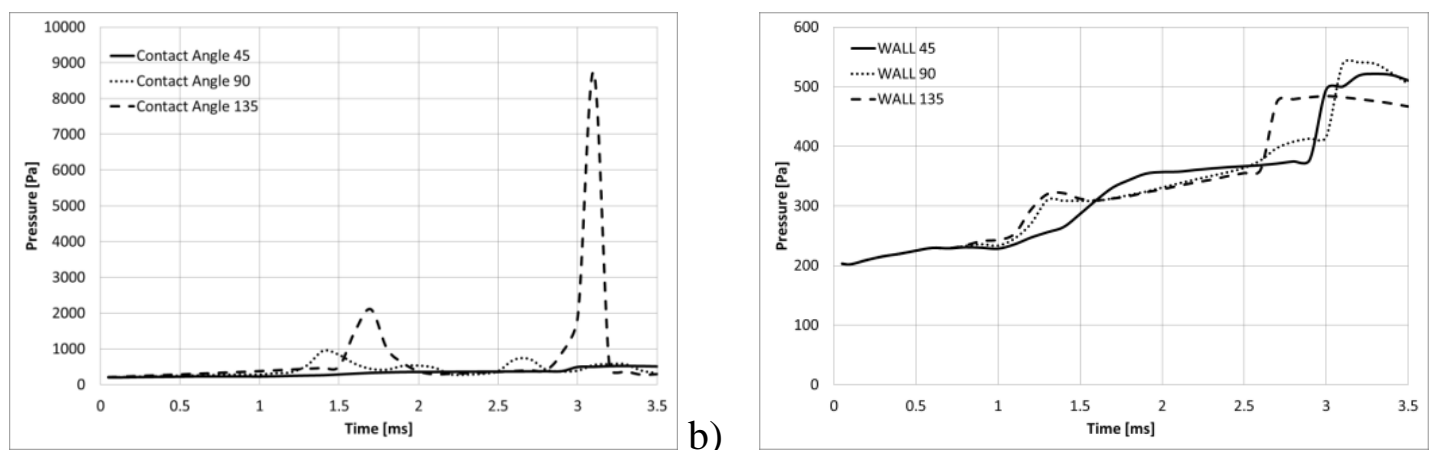
c)

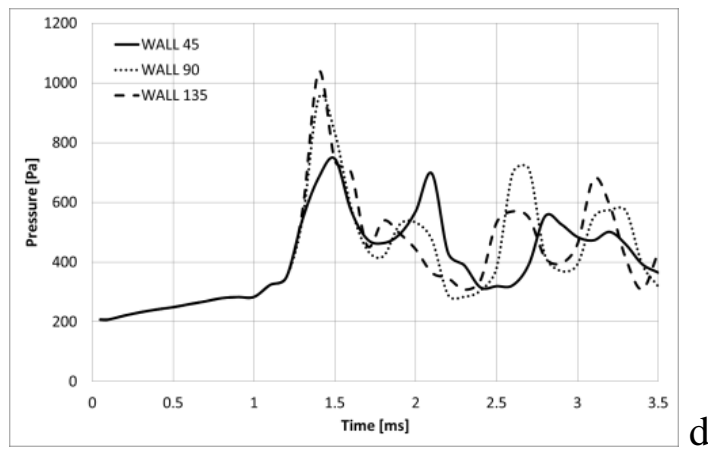

d)

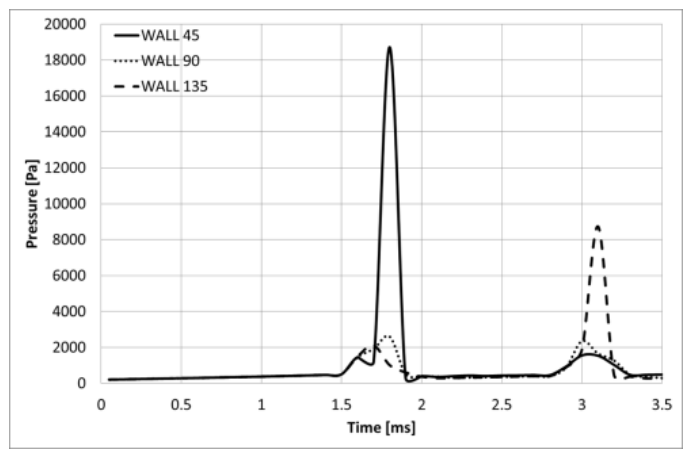

Figure 2. Pressure drop in the channel, a) different contact angles for all walls, b) different wall contact angles for hydrophilic GDL, c) different wall contact angle for moderate GDL,and d) different wall contact angle for hydrophobic GDL.

\section{Water in the channel}

Water in the channel is the amount of water contained in the domain at a specific time. It is calculated by dividing the number of cells containing water at a specific time by the total number of cells in the domain. The amount of water in the channel represents the amount of water trapped in the channel due to the surfaces' wettability which may affect the humidity level in the gas channel. It is also necessary to work out any relation to the water discharge time.

Figure 3a gives comparison of water in the channel for the general cases of different GDL wettability. The hydrophobic and moderate scenarios are almost the same with the moderate scenario occupying more volume of the channel due to the slower movement of the wavy droplets and the neutral contact angle of both the GDL and wall. For the hydrophilic case water occupies the most among three cases because water spread out on all surfaces due to the low contact angle, moreover, It has been noticed that the time of the drop in water content is also the time when water move out of the channel.

Figures 3b,c,d show the effect of wall wettability on the amount of water in the microchannel for different GDL wettabilities (i.e. hydrophilic, moderate, and hydrophobic). Figure 3b shows for a hydrophilic GDL the change of wall wettability from hydrophobic to hydrophilic increases the water in the channel from $16 \%$ to $18 \%$ which is the highest among the three scenarios; furthermore the water takes longer to leave the channel as the wall wettability is changed from hydrophobic to hydrophilic. Figure 3c shows for a moderate GDL the water still takes longer to leave the channel as the wall wettability is changed from hydrophobic to hydrophilic, however water occupy less of the channel compared to the hydrophilic GDL scenario (i.e. $10.5 \%$ to $12 \%$ ). Water occupies more of the channel in the second coalesced droplet for a hydrophilic wall because of water remaining on the wall from the previous droplet. For a hydrophobic GDL (cf. Figure 3d) it takes the same duration for the water to start moving out of the channel and the wall wettability doesn't the highest water occupancy especially for the first coalesced droplet (i.e. 11\%). 
a)

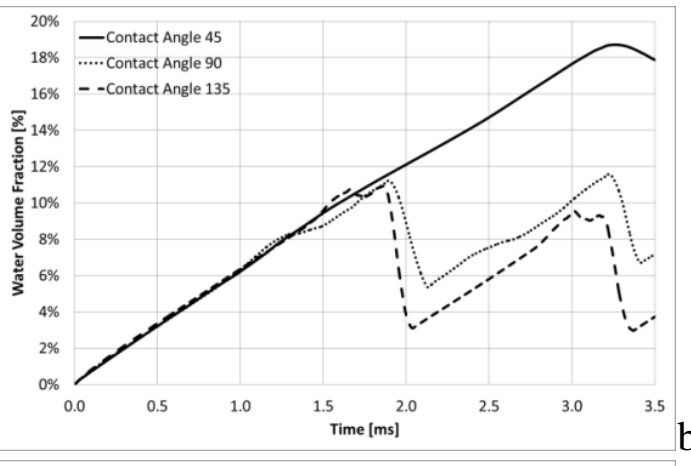

b)

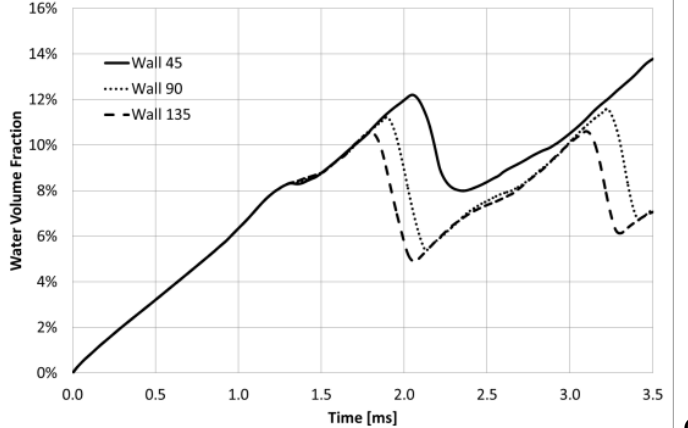

d)

c)
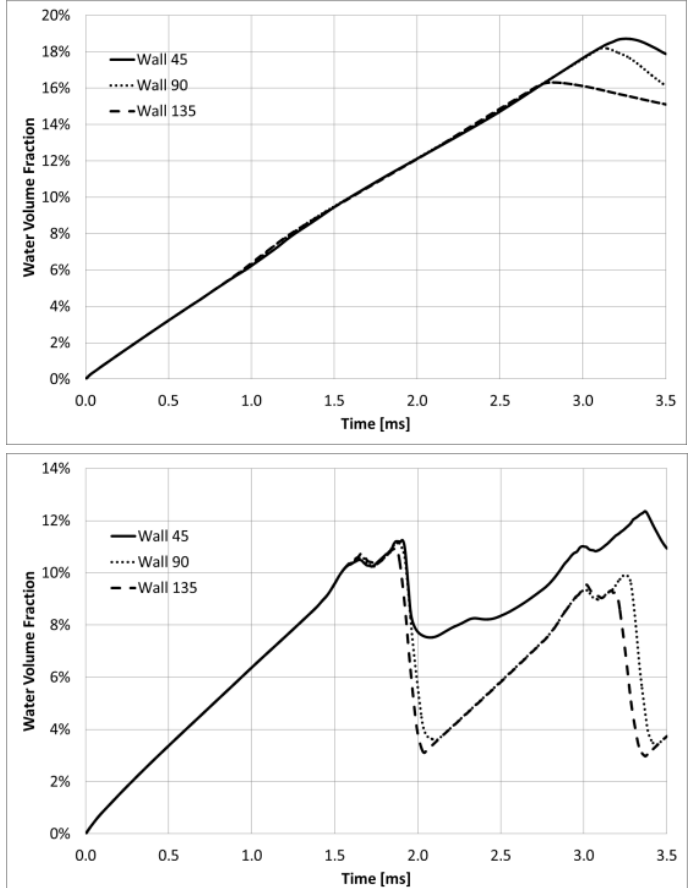

Figure 3. Water fraction in the channel, a) different contact angles for all walls, b) different wall contact angles for hydrophilic GDL, c) different wall contact angle for moderate GDL,and d) different wall contact angle for hydrophobic GDL.

Water on the GDL

Water coverage of the GDL is the area of the GDL that is covered by water. It is calculated by dividing the number of cells containing water on the GDL surface by the total number of cells forming the GDL surface. Even though the GDL was treated as a solid surface in the simulation, the water coverage could be used to understand the amount of water covering the GDL and might diffuse back into the MEA.

Figure 4a gives comparison of water on the GDL for the general cases of different GDL wettability. For the hydrophobic case water cover the least among three cases because of droplet formation due to high surfaces contact angle. Cyclic behaviour is observed where the coalesced droplets move out of the channel when the water volume fraction drops. A random continuous behaviour is observed for the moderate case with water volume fraction in between the other two cases. For the hydrophilic case the water on the GDL, which is the highest among three cases, increases as time progresses due to low GDL contact angle and a continuous behaviour is observed.

Figure 4b,c,d shows the effect of wall wettability on the amount of water on the GDL for different GDL wettabilities (i.e. hydrophilic, moderate, and hydrophobic). Figure 4b shows the water on the GDL for the hydrophilic GDL where the hydrophobic wall scenario has the highest water coverage due to the water being rejected from the wall for its high contact angle, furthermore, since a film layer is formed due to the low contact angle of the GDL the water covers the highest among the three scenarios. Figure 4c shows a random behaviour of the water on the GDL for a moderate GDL where the hydrophilic wall has the least variation water covering the surface and the moderate and hydrophobic wall have a similar behaviour. The water on the GDL for a hydrophobic GDL (cf. Figure 4d) has a cyclic behaviour with the moderate wall having the highest water content due to the wall contact angle that doesn't move the water away from the GDL toward the wall nor toward the centre of the channel. 
The hydrophilic wall has the lowest water covering the GDL because the low wall contact angle move the water toward the wall corners as soon as it reaches the wall surface.

a)

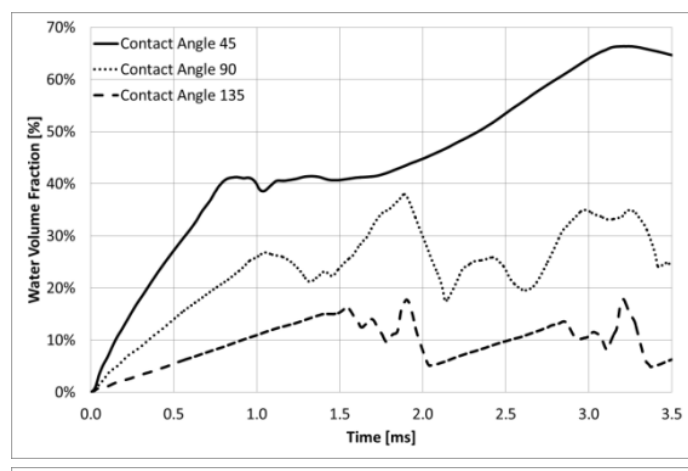

c)

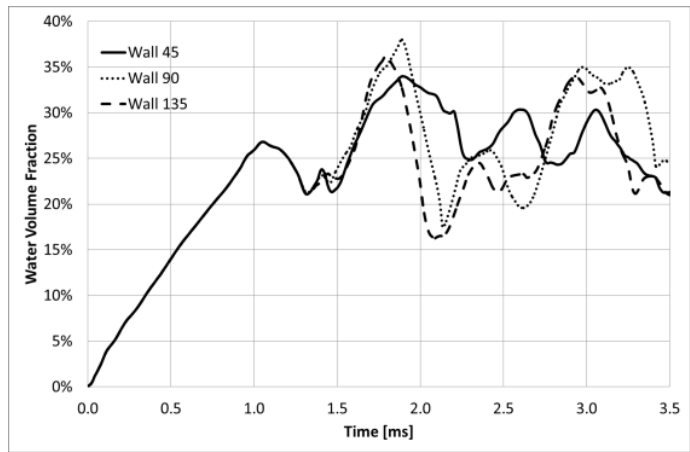

b)

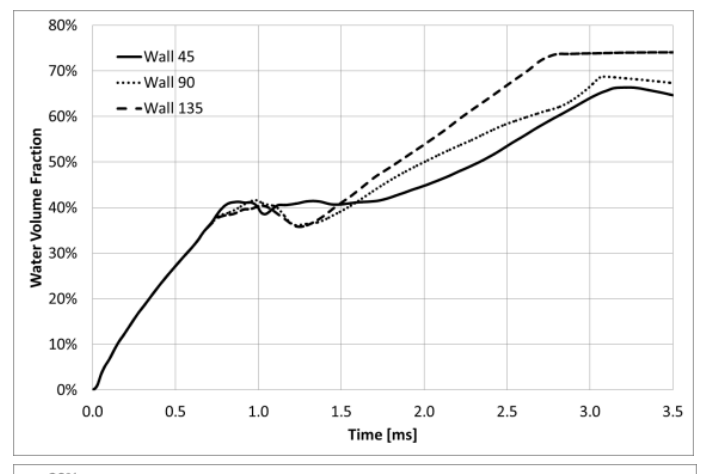

d)

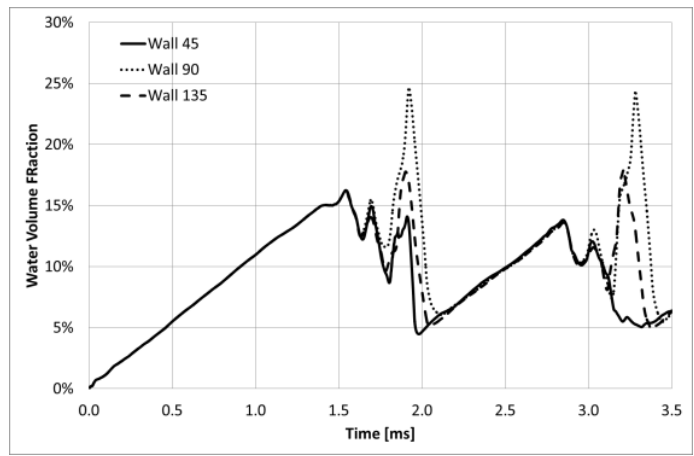

Figure 4. Water fraction on the GDL surface, a) different contact angles for all walls, b) different wall contact angles for hydrophilic GDL, c) different wall contact angle for moderate GDL,and d) different wall contact angle for hydrophobic GDL.

\section{Conclusion}

A numerical study has been conducted to examine the effect of different combinations of wall and GDL wettabilities on the dynamic behaviour of water droplets in a micro-channel representing a PEM fuel cell gas channel. Three-dimensional CFD modelling was used for the study with the use of the volume-of-fluid method. The micro-channel has a square crosssection with the bottom wall representing the gas diffusion layer (GDL), and the sidewalls and top wall representing the channels ribs and cover. Three pores on the GDL were used to introduce water into the micro-channel. Three contact angles were chosen to represent different wettabilities for the wall and GDL. Total of nine simulations were conducted and compared. The main findings from this study are:

- Different combinations of contact angles show different profiles for the pressure difference, water in the channel, and Water on the gas diffusion layer.

- Three main patterns were observed in the results, continuous, random cyclic and uniform cyclic. The uniform cyclic pattern is more useful for a periodic purge to remove water from the gas channel than the other observed patterns.

- The GDL wettability has a greater impact on the water droplet behaviour than the wall wettability.

- In terms of pressure drop, the size of water volume that blocks the micro-channel increase as the contact angle of the GDL increase which leads to an increase in the pressure drop.

- In terms of water in the channel, there is no significant difference between a hydrophobic and a moderate GDL, however, the amount of domain water occupancy 
increase dramatically for a hydrophilic GDL. Furthermore, a hydrophilic wall always has the highest water ratio in all GDL wettabilities.

- In terms of water on the GDL, as the contact angle of the GDL increase, the water coverage decrease. The hydrophilic wall has the minimal water ratio variation for the moderate and hydrophobic GDL scenarios.

\section{Acknowledgement}

The Author gratefully acknowledges the support of ANASYS, Inc. of UK.

\section{References}

1. Y. Wang, K. S. Chen, J. Mishler, S. C. Cho, and X. C. Adroher. Applied Energy, 88 (4) (2011) 981-1007.

2. C.Y. Wang. Chemical reviews, 104 (10) (2004) 4727-4765.

3. K. Jiao and X. Li. Progress in Energy Combustion Science, 37 (3) (2011) 221-291.

4. A. Turhan, S. Kim, M. Hatzell, and M. M. Mench. Electrochimica Acta, 55 (8) (2010) 2734-2745.

5. J. Owejan, T. Trabold, D. Jacobson, M. Arif, and S. Kandlikar. International Journal of Hydrogen Energy, 32 (17) (2007) 4489-4502.

6. W. Zhu, Z. W. Dunbar and R. I. Masel. Society, 16 (2) (2008) 995-1000.

7. C. W. Hirt and B. D. Nichols. Journal of Computational Physics, 39 (1) (1981) 201225.

8. A. Theodorakakos, T. Ous, M. Gavaises, J. M. Nouri, N. Nikolopoulos, and H. Yanagihara. Journal of colloid and interface science, 300 (2) (2006) 673-87.

9. Y. Cai, J. Hu, H. Ma, B. Yi, and H. Zhang. J. Power Sources, 161 (2) (2006) 843-848.

10. A. D. Le and B. Zhou. J. Power Sources, 182 (2008) 197-222.

11. X. Zhu, Q. Liao, P.C. Sui, and N. Djilali. J. Power Sources, 195 (3) (2010) 801-812.

12. A. Theodorakakos and G. Bergeles. International Journal for Numerical Methods in Fluids, 45 (4) (2004) 421-439.

13. X. Zhu, Q. Liao, P.C. Sui, and N. Djilali. J. Power Sources, 195 (3) (2010) 801-812.

14. X. Zhu, P.C. Sui, and N. Djilali. J. Power Sources, 181 (1) (2008) 101-115.

15. X. Zhu, P.C. Sui, N. Djilali, and Q. Liao. Fuel Cells, 11 (3) (2011) 404-412.

16. J. Martin, P. Oshkai, and N. Djilali. Journal of Fuel Cell Science and Technology, 2 (1) (2005) 70-80.

17. Fluent, Fluent 13.0.0 User's Guide, Fluent Inc., 2010.

18. S. Litster, D. Sinton, and N. Djilali. J. Power Sources, 154 (1) (2006) 95-105.

19. S. Litster, J.G. Pharoah, G. Mclean, and N. Djilali. J. Power Sources, 156 (2006) 334344.

20. X. Zhu, P.C. Sui, and N. Djilali. J. Power Sources, 172 (1) (2007) 287-295.

21. J. Franzini and E. Finnemore, Fluid mechanics with engineering applications. $10^{\text {th }}$ edition. McGraw-Hill. Boston, MA (2001).

22. P.C. Sui and N. Djilali. ASME J. of Fuel Cell Science \& Technology, 2 (3) (2005) 149-155.

23. A. Bazylak, D. Sinton, Z. Liu, and N. Djilali. J. Power Sources, 163 (2) (2007) 784792.

24. E. C. Kumbur, K. V. Sharp, and M. M. Mench. J. Power Sources, 161 (1) (2006) 333345. 